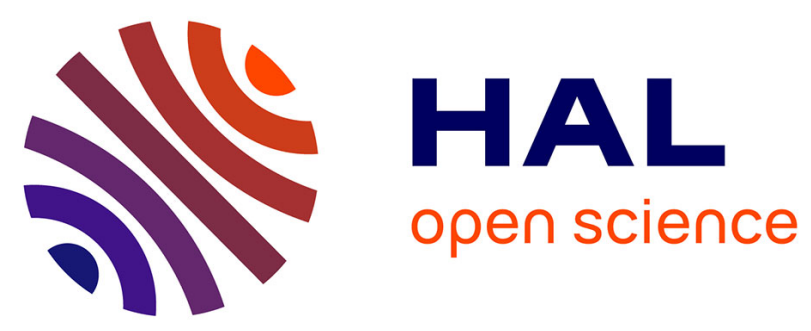

\title{
Second redo surgery after two consecutive failures of a colorectal or coloanal anastomosis: is it reasonable?
}

\author{
Camélia Labiad, Marie Monsinjon, Massimo Giacca, Yves Panis
}

\section{To cite this version:}

Camélia Labiad, Marie Monsinjon, Massimo Giacca, Yves Panis. Second redo surgery after two consecutive failures of a colorectal or coloanal anastomosis: is it reasonable?. International Journal of Colorectal Disease, In press, 10.1007/s00384-021-03982-y . hal-03277803

\section{HAL Id: hal-03277803 \\ https://hal.sorbonne-universite.fr/hal-03277803}

Submitted on 5 Jul 2021

HAL is a multi-disciplinary open access archive for the deposit and dissemination of scientific research documents, whether they are published or not. The documents may come from teaching and research institutions in France or abroad, or from public or private research centers.
L'archive ouverte pluridisciplinaire HAL, est destinée au dépôt et à la diffusion de documents scientifiques de niveau recherche, publiés ou non, émanant des établissements d'enseignement et de recherche français ou étrangers, des laboratoires publics ou privés. 
Second redo surgery after two consecutive failures of a colorectal or coloanal anastomosis.

\title{
Is it reasonable?
}

\author{
Camélia Labiad $^{1,2}$, Marie Monsinjon ${ }^{1}$, Massimo Giacca ${ }^{1}$ and Yves Panis ${ }^{1}$ \\ 1 Department of Colorectal Surgery, Pôle des Maladies de l'Appareil Digestif (PMAD), Beaujon \\ Hospital, Assistance Publique-Hôpitaux de Paris (AP-HP), University of Paris, 100 Boulevard du \\ Général Leclerc, 92110, Clichy, France
}

2 Sorbonne Université, 15-21 rue de 1'Ecole de Médecine, 75006, Paris, France

Original article. 1495 words.

No financial disclosure or conflict of interest from any of the author.

Address for correspondence and reprints:

Professor Yves Panis, M.D., Ph.D., Service de Chirurgie Colorectale, Pôle des Maladies de l'Appareil Digestif, Hôpital Beaujon - Assistance Publique des Hôpitaux de Paris (APHP), Université of Paris, 100 boulevard du Général Leclerc, 92110 Clichy, France (Tel: +331408745 47; Fax: +33 1408744 31; E-mail: yves.panis@aphp.fr 


\begin{abstract}
Purpose: Colorectal redo surgery is well known to be a difficult procedure, associated with a high risk of failure. The aim of this study was to look into patients presenting two consecutive failed colorectal (CRA) or coloanal (CAA) anastomosis who underwent a second redo surgery (i.e. third anastomosis).
\end{abstract}

Methods: A retrospective study based on a prospective database of second redo surgeries of CRA or CAA, in an expert center. Sixteen patients between 2005 and 2020 were analyzed.

Results: After a mean follow-up of $28 \pm 26$ months, success of surgery (defined as no stoma at the end of follow-up) was reported in 10/16 patients (63\%). One patient with chronic anastomotic leakage and another with early colonic ischemia had no defunctioning stoma reversal. In the remaining four patients with a failed second redo surgery, a definitive stoma was ultimately created for fistula recurrence $(n=1)$, poor functional results $(n=2)$ or local cancer recurrence $(n=1)$. Two risk factors for failure of this second redo surgery were significantly found in an univariate analysis: 1) nature of the primary anastomosis: $3 / 13$ second redo surgeries failed (23\%) if a CRA was first made and $3 / 3(100 \%)$ if it was a CAA $(\mathrm{p}=0.036) ; 2)$ age: patients with a failed second redo surgery were older $(\mathrm{p}=0.04)$.

Conclusion: A 63\% rate of success of second redo surgery was observed after two failed CRA or CAA. Although a demanding procedure, it can be proposed to carefully selected and motivated patients.

Keywords: colorectal anastomosis, coloanal anastomosis, redo surgery, chronic pelvic sepsis 
The post-operative course of a colorectal (CRA) or coloanal anastomosis (CAA) can be complicated by anastomotic leakage, chronic pelvic sepsis or stenosis, which can expose the patient to poor quality of life. In this difficult situation, we[1] and others[2-5] showed that redo surgery (RS) with the construction of a new anastomosis can avoid the need for a definitive stoma in 69 to $80 \%$ of cases. However, despite this RS, recurrent anastomotic failure was present in at least a quarter of patients[1, 3, 5]. To the best of our knowledge, no data exists concerning the possibility of a second RS. The aim of our study was to report our experience of a series of patients who underwent a second RS after failure of two previous CRA or CAA.

All patients who underwent a third CRA or CAA between November 2005 and September 2020 were included. Patients with an ileal pouch-anal anastomosis or a local transanal approach were excluded. Data from a prospectively maintained database were analyzed retrospectively.

Mortality was defined as death occurring within 90 days after surgery. Postoperative morbidity was classified according to Dindo et al[6] and considered any complication during the hospital stay or within 30 days of the surgery.

Our primary endpoint was success rate of the second RS, defined as patient without stoma nor chronic pelvic sepsis/anastomotic leakage at the end of follow-up. Postoperative morbidity was a secondary endpoint.

Results are presented as the mean \pm standard deviation (range) for continuous variables and number (percentage) for categorical variables. Student's t-test was used for continuous variables and Fisher's exact test for categorical variables. All tests with a 2 -sided P value less than 0.05 were considered significant. Analysis were performed using JMP software (version 14.0.0; SAS Institute, Cary, NC).

The manuscript was prepared according to the Strengthening the Reporting of Observational studies in Epidemiology (STROBE) statement [7]. 
Sixteen patients were included, with a mean age at first surgery of $52 \pm 17$ [2-73] years, and $9(56 \%)$ were male.

Primary operation was performed for colorectal cancer $(n=12)$, sigmoid diverticulitis $(n=1)$, colonic angioma $(n=1)$, radiation-induced sigmoiditis $(n=1)$ or colonic stenosis of unknown reason $(n=1)$. The operation was a stapled CRA in 13 patients $(81 \%)$ and a hand-sewn CAA in 3 patients (19\%). Among them, 7 (44\%) had history of pelvic radiotherapy, performed in a neoadjuvant setting for rectal cancer in 6 patients and for uterus cancer in one patient. A defunctioning stoma was performed in 8 patients (50\%). After failure of the primary operation, 5 patients $(31 \%)$ needed a Hartmann's procedure with end colostomy (4 had an emergency surgery for peritonitis and one for stenosis).

Details of first and second RS and their postoperative morbidity are described in Table 1.

Nine patients $(56 \%)$ required first RS because of anastomotic leakage, 2 (13\%) because of anastomotic stricture, $4(25 \%)$ for tumor recurrence and one (6\%) for colonic ischemia. In 5/16 (31\%) patients, first RS was a stapled CRA and in the remaining 11 (69\%), a manual CAA. Among those 11 patients, $8(50 \%)$ had a delayed coloanal pull-through anastomosis (DCAA). A defunctioning stoma was performed in 12 patients (75\%). After failure of the first RS, 4 patients (25\%) required a Hartmann's procedure for anastomotic leakage, and 3 of them had peritonitis then. Before second RS, 8 patients (50\%) still had a diverting ileostomy or had a new stoma created after postoperative complications, and 14 patients $(88 \%)$ had a history of 3 or more open procedures (primary surgery, first RS, interventions for liver metastasis, complications, etc).

Second RS and third anastomosis were performed for anastomotic leakage in 13 patients $(81 \%)$, for stenosis in $2(13 \%)$ and one had colonic ischemia $(6 \%)$. A new CAA was created in 15 patients (94\%), and a mechanical CRA in the remaining patient (6\%). All 16 patients had a diverting stoma after this surgery. In 11 patients (69\%), strong intraoperative difficulties were described, due to multiple adhesions and a complicated pelvic dissection. 4/16 patients (20\%) 
needed a Deloyers maneuver[8] (3 of them for a CAA). 13 patients among the 15 who had a CAA (87\%) required a DCAA with new manual CAA created after a mean delay of 9 days (3-22).

There were no deaths within 90 days after this second RS (and third anastomosis) and the overall morbidity rate was $63 \%$. One patient $(6 \%)$ needed an early reoperation for colonic ischemia. After second RS, 14/16 patients had stoma closure (88\%). Two patients didn't because of chronic anastomotic leakage $(n=1)$ and early colonic ischemia leading to a definitive colostomy $(n=1)$. Among the 14 patients undergoing stoma closure, $10(63 \%)$ had a functional anastomosis at the end of a mean follow-up of $28 \pm 26$ months (3-91). In the remaining four, a stoma was ultimately needed for fistula recurrence $(n=1)$, poor functional results $(n=2)$ or local cancer recurrence $(n=1)$. Thus, failure rate of the second RS concerned at the end of follow-up 6/16 patients $(38 \%)$.

After univariate analysis, two risk factors for failure of the second RS were observed: 1) Failure rate was 3/13 (23\%) if a CRA was the primary operation versus 3/3 (100\%) if it was a CAA $(\mathrm{p}=0.036) ; 2)$ Patients with failure were significantly older $(\mathrm{p}=0.04)$.

In our study, the main reason for performing a second RS was chronic leakage, observed in $81 \%$ of our patients. It has been shown that recurrent anastomotic leakage and/or pelvic sepsis occurs in $16 \%$ of first RS[9]. Others[1-5] have focused on the outcomes of first RS with relatively high morbidity rates (26 to $55 \%$ ) but good success rates (78 to 100\%). Among these studies, 2 even reported a $100 \%$ success rate but indication for RS was in 40\%[2] and in 100\%[4] of patients anastomotic stricture, therefore with a lower risk of new leakage than in case of chronic leakage and/or pelvic sepsis. Both Pitel et al.[3] and Woo et al.[5] observed a 79\% rate of stoma-free patients at the end of follow-up, with $15 \%$ and $22 \%$ included patients with anastomotic stenosis respectively, which is similar to the rate observed in the present study focusing on second RS (13\%). The recent review [9] on RS (which included four of these five studies) also showed a global 
success rate of $79 \%$ after first RS. As far as we know, no information exists concerning the risk of recurrent leakage after a second RS for the same indication.

After two consecutive failures, most authors would probably consider definitive stoma the best option. In this setting, transanal colonic pull-through with delayed coloanal anastomosis (DCAA) seems the most appropriate approach and was used in $81 \%$ of our patients. We previously showed that DCAA after failed CRA or CAA with chronic pelvic sepsis or rectovaginal fistula could avoid a permanent stoma in $79 \%$ of patients with acceptable functional results[10] (i.e. a mean low anterior resection syndrome score of $22 \pm 9$ (9-39)). This technique was first described $[11,12]$ as a way to avoid diverting ileostomy after rectal excision. However, in the present study and because the risk of failure is considered very high, we performed a DCAA with systematic temporary ileostomy, in order to increase the chances of success of this second RS. Indeed, if pelvic sepsis is still present around day 8-10, we usually reoperate for partial resection of the colonic stump, in order to make the patient more comfortable for discharge, but the manual CAA is delayed around week 2 or 3 after DCAA without any risk or discomfort for the patient since a diverting stoma is present. Lastly, during this second RS (but also during first RS), any J-pouch or side-to-end anastomosis must be strongly avoided, not only because of the pelvic sepsis, but also because the remaining colon after two previous operations could be strongly shortened. A tensionfree anastomosis is mandatory, and therefore the splenic flexure should be mobilized and the inferior mesenteric vein always high ligated if not performed in the previous surgeries. Furthermore, $25 \%$ of our patients required a Deloyers maneuver[8] in order to obtain a tension-free anastomosis.

Although our number of patients is relatively small, we were able to assess possible risk factors of failure of this second RS. Indeed, we found in an univariate analysis that primary CRA was more associated with success of the second RS than a primary CAA. We already observed[1] that the primary anastomosis influenced the failure rate of restoring the intestinal continuity during a first RS: $56 \%$ of failure if the prior anastomosis was a CAA vs $8 \%$ if it was a CRA. Furthermore, 
age was also a risk of failure of this third anastomosis. It probably underlines that it must only be proposed in selected motivated patients, as suggested in the present study where no mortality was noted.

In conclusion, our study indicates that a second RS after two failed previous CRA or CAA is a demanding procedure but remains safe and feasible, notably in younger patients whose primary surgery was a CRA, as it allowed $63 \%$ of them to be free of stoma. 


\section{REFERENCES}

1. Lefevre JH, Bretagnol F, Maggiori L, Ferron M, Alves A, Panis Y (2011) Redo surgery for failed colorectal or coloanal anastomosis: A valuable surgical challenge. Surgery. 149:65-71

2. Genser L, Manceau G, Karoui M, Breton S, Brevart C, Rousseau G, Vaillant J-C, Hannoun L (2013) Postoperative and long-term outcomes after redo surgery for failed colorectal or coloanal anastomosis: retrospective analysis of 50 patients and review of the literature. Dis Colon Rectum. 56:747-755

3. Pitel S, Lefèvre JH, Tiret E, Chafai N, Parc Y (2012) Redo coloanal anastomosis: a retrospective study of 66 patients. Ann Surg. 256:806-810; discussion 810-811

4. Schlegel RD, Dehni N, Parc R, Caplin S, Tiret E (2001) Results of reoperations in colorectal anastomotic strictures. Dis Colon Rectum. 44:1464-1468

5. Woo IT, Park JS, Choi G-S, Park SY, Kim HJ, Park IK (2018) Clinical Outcomes of a Redo for a Failed Colorectal or Coloanal Anastomosis. Ann Coloproctol. 34:259-265

6. Dindo D, Demartines N, Clavien P-A (2004) Classification of Surgical Complications: A New Proposal With Evaluation in a Cohort of 6336 Patients and Results of a Survey. Annals of Surgery. 240:205-213

7. von Elm E, Altman DG, Egger M, Pocock SJ, Gøtzsche PC, Vandenbroucke JP (2007) The Strengthening the Reporting of Observational Studies in Epidemiology (STROBE) statement: guidelines for reporting observational studies. The Lancet. 370:1453-1457 
8. Deloyers L (1958) [Technic permitting the easy assurance of continuity of the colon \& conservation of sphincter after excision of the left transverse hemicolon \& entire left colon; possible inclusion of rectum]. J Chir (Paris). 75:147-155

9. Westerduin E, Klaver CEL, van Geloven AAW, Westerterp M, Bemelman WA, Tanis PJ (2018) Outcome After Redo Surgery for Complicated Colorectal and Coloanal Anastomosis: A Systematic Review. Dis Colon Rectum. 61:988-998

10. Maggiori L, Blanche J, Harnoy Y, Ferron M, Panis Y (2015) Redo-surgery by transanal colonic pull-through for failed anastomosis associated with chronic pelvic sepsis or rectovaginal fistula. Int J Colorectal Dis. 30:543-548

11. Turnbull RB, Cuthbertson A (1961) Abdominorectal pull-through resection for cancer and for Hirschsprung's disease. Delayed posterior colorectal anastomosis. Cleve Clin Q. 28:109-115

12. Cutait DE, Figliolini FJ (1961) A new method of colorectal anastomosis in abdominoperineal resection. Dis Colon Rectum. 4:335-342 
Table 1: Operative findings and postoperative morbidity of 16 patients who underwent a first and a second redo surgery after two previous failed colorectal or coloanal anastomosis.

\begin{tabular}{|c|c|c|}
\hline & $\begin{array}{l}\text { First redo surgery } \\
\mathrm{n}(\%)\end{array}$ & $\begin{array}{c}\text { Second redo surgery } \\
\mathrm{n}(\%)\end{array}$ \\
\hline $\begin{array}{l}\text { Age at the time of redo surgery } \\
\text { (years) }\end{array}$ & $\begin{array}{c}54 \pm 15 \\
{[16-74]^{\mathrm{a}}}\end{array}$ & $\begin{array}{c}56 \pm 13 \\
{[30-74]}\end{array}$ \\
\hline $\begin{array}{l}\text { Delay since the previous surgery } \\
\text { (months) }\end{array}$ & $\begin{array}{c}23 \pm 40 \\
{[0-170]}\end{array}$ & $\begin{array}{c}27 \pm 41 \\
{[0-172]}\end{array}$ \\
\hline \multicolumn{3}{|l|}{ New procedures } \\
\hline After Hartmann procedure & $5(31)^{b}$ & $4(25)$ \\
\hline Stapled colorectal anastomosis & $5(31)$ & $1(6)$ \\
\hline Hand-sewn coloanal anastomosis & $11(69)$ & $15(94)$ \\
\hline Diverting stoma & $12(75)$ & $16(100)$ \\
\hline \multicolumn{3}{|l|}{$\begin{array}{l}\text { Techniques required to perform } \\
\text { the anastomosis }\end{array}$} \\
\hline Deloyers maneuver & $0(0)$ & $4(25)$ \\
\hline Coloanal delayed anastomosis & $8(50)$ & $13(81)$ \\
\hline Operating time (min) & $\begin{array}{c}278 \pm 62 \\
{[180-480]}\end{array}$ & $\begin{array}{c}305 \pm 109 \\
{[210-540]}\end{array}$ \\
\hline \multicolumn{3}{|l|}{$\begin{array}{l}\text { Post-operative morbidity within } 30 \\
\text { days }\end{array}$} \\
\hline Dindo 0 & $8(50)$ & $6(38)$ \\
\hline Dindo I & $1(6)$ & $1(6)$ \\
\hline Dindo II & $1(6)$ & $4(25)$ \\
\hline Dindo III & $3(19)$ & $5(31)$ \\
\hline Dindo IV & $3(19)$ & $0(0)$ \\
\hline Anastomotic leakage & $4(25)$ & $0(0)$ \\
\hline Isolated pelvic abscess & $1(6)$ & $4(25)$ \\
\hline Post-operative ileus & $1(6)$ & $1(6)$ \\
\hline Colonic ischemia & $1(6)$ & $1(6)$ \\
\hline
\end{tabular}

${ }^{a}$ Mean \pm standard deviation [range]

${ }^{\mathrm{b}}$ Number of patients (percentage of patients) 